\title{
FIRESIG - SISTEMA DE SUPORTE A TOMADA DE DECISÃO PARA O COMBATE A INCÊNDIOS NO PARANÁ
}

\author{
Flavio Deppe ${ }^{1}$ \\ Eduardo Vedor de Paula ${ }^{2}$ \\ Jackson Vosgerau ${ }^{3}$ \\ Alexandre Guetter ${ }^{4}$
}

\begin{abstract}
RESUMO
O FIRESIG representa um sistema de suporte a tomada de decisão para o combate a incêndios no Estado do Paraná. O FIRESIG atende as demandas específicas de atividades de monitoramento, prevenção e combate a incêndios. Os usuários institucionais do FIRESIG se referem ao Instituto Ambiental do Paraná (IAP) e a Coordenadoria Estadual de Defesa Civil do Paraná. O FIRESIG oferece ferramentas para: (i) entrada de dados de focos de calor, índice de vegetação e índice de risco de incêndio, (ii) espacialização, visualização e análise de focos de calor, (iii) identificação de recursos e infra-estrutura disponível para combate aos incêndios, (iv) atualização da base de dados dos recursos disponíveis para o combate aos incêndios, (v) determinação de melhores rotas de acesso aos incêndios. A utilização do FIRESIG reduz o tempo de resposta para o combate aos incêndios e auxilia a montagem de estratégias de combate. O FIRESIG é caracterizado como um sistema de suporte a tomada de decisão, robusto e de baixo custo para combate aos incêndios. Além do mais pode ser adaptado para ser utilizado em outros tipos de desastres ambientais.

Palavras chave: sistema de suporte a tomada de decisão, incêndios, SIG, desastres ambientais
\end{abstract}

\section{FIRESIG - DECISION SUPPORT SYSTEM FOR FIRE FIGHT IN PARANÁ}

\begin{abstract}
The FIRESIG represents a decision support system for fire fight in the Paraná State. The FIRESIG meets specific demands for monitoring, prevention and fire fight. The system's users are the Paraná Environmental Institute and the Paraná Civil Defense Coordination. The FIRESIG offers several tools for: (i) hot spots, vegetation index and fire risk index data input, (ii) mapping, visualization and hot spots analysis, (iii) identification of available resources and infrastructure for fire fight, (iv) data base update, (v) determination of firefight best routes. The use of FIRESIG reduces fire fight response time and helps the fire fight strategy definition. The FIRESIG can be considered as robust and a low price fire fight system. Additionally, the system can be adapted for use as a decision support system for other environmental disasters.
\end{abstract}

Key words: decision support system, fires, GIS, environmental disasters

\section{INTRODUÇÃO}

O presente trabalho corresponde ao desenvolvimento de um sistema de suporte a tomada de decisão para combate a incêndios no Estado do Paraná. O sistema inicialmente foi concebido pela Christian Albrechts University, Alemanha (Schoppenhorst, 2002) e posteriormente adaptado e customizado pelo Instituto Tecnológico SIMEPAR, e denominado FIRESIG, especificamente para atender atividades do Instituto Ambiental do
Paraná (IAP) e a coordenadoria da Defesa Civil do Paraná. O sistema é baseado em plataforma de SIG (Sistema de Informações Geográficas), customizada para atender demandas e requerimentos específicos para atividades de monitoramento, prevenção e combate de incêndios. Dados de focos de calor e do estado da vegetação são obtidos através do pré-processamento e processamento de imagens NOAA/AVHRR, capturadas pela

\footnotetext{
deppe@simepar.br, Ph.D., Instituto Tecnológico SIMEPAR, Centro Politécnico da UFPR, Caixa Postal 19.100, CEP 81.531-990, Curitiba, PR, Brasil, Tel.: +55 41 366-1133, Ramal 2108

2 eduardo@simepar.br, Geógrafo, Instituto Tecnológico SIMEPAR, Centro Politécnico da UFPR, Caixa Postal 19.100, CEP 81.531-990, Curitiba, PR, Brasil, Tel.: +55 41 366-1133, Ramal 2111

3 jackson@pr.gov.br, Eng. Florestal, Instituto Ambiental do Paraná, Rua Engenheiro Rebouças, 1206, CEP 80.215-100, Curitiba, PR, Brasil, Tel.: +55 41 213-3828

4 guetter@simepar.br, Ph.D., Instituto Tecnológico SIMEPAR, Centro Politécnico da UFPR, Caixa Postal 19.100, CEP 81.531-990, Curitiba, PR, Brasil, Tel.: +55 41 366-1133, Ramal 2311
} 
Estação de Recepção de Imagens do SIMEPAR. Dados do índice de risco de incêndio florestal são processados a partir da rede telemétrica de estações meteorológicas do SIMEPAR.

O FIRESIG foi customizado e oferece ferramentas para: (i) importação de dados, (ii) espacialização e visualização, (iii) análise de focos de calor, (iv) acesso a base de dados, (v) determinação de estruturas de combate mais próximas aos incêndios, (vi) atualização de dados, (vii) definição de melhores rotas, (viii) saída de dados. Além dos dados e informações estáticos, as informações de focos de calor, índice de risco de incêndio e do estado da vegetação (índice de vegetação), são incorporadas em tempo quase real e a utilização do sistema reduz o tempo de resposta para o combate a incêndios. Em função de sua arquitetura, o sistema pode ser adaptado para ser utilizado em outras áreas e caracterizado como um sistema de tomada de decisão para combate de incêndios robusto e de baixo custo.

\section{MATERIAL E MÉTODOS}

O conjunto de dados utilizado no sistema foi organizado em plataforma de SIG, na qual os planos de informação (layers) são integrados por meio de uma interface desenvolvida especificamente para a sobreposição de dados, visualização e análise. O software customizado se refere ao ArcView GIS 3.2 e suas extensões.

Os dados e informações (tabela 1) são classificados como estáticos ou dinâmicos. Os primeiros correspondem a dados sobre a caracterização físico-territorial, entidades administrativas, dados logísticos, e imagens de satélite Landsat, Os dados estáticos dispensam constante atualização. Já os dados dinâmicos sofrem atualização diária, garantindo o dinamismo e a alta resolução temporal do sistema.

Tabela 1: Planos de Informação (layers)

Table 1: Layers

\begin{tabular}{ll}
\hline \multicolumn{1}{c}{ Descrição } & Tipo \\
\hline Focos de Calor & Dinâmico \\
\hline Estado da Vegetação & Dinâmico \\
\hline Índice de Risco de Incêndio Florestal (RIF) & Dinâmico \\
\hline Contorno do Estado do Paraná & Estático \\
\hline Divisões Municipais & Estático \\
\hline Sedes Municipais & Estático \\
\hline Malha Viária Principal & Estático \\
\hline Malha Viária Secundária & Estático \\
\hline Rede Hidrográfica & Estático \\
\hline Linhas de Transmissão de Energia Elétrica & Estático \\
\hline Imagens LANDSAT-TM & Estático \\
\hline Topografia (USGS) & Estático \\
\hline Vegetação (USGS) & Estático \\
\hline Unidades de Conservação & Estático \\
\hline Grupamentos do Corpo de Bombeiro & Estático \\
\hline Escritórios do Instituto Ambiental do Paraná & Estático \\
\hline Postos Polícias Florestal, Rodoviária Estadual e Federal & Estático \\
\hline
\end{tabular}

Os focos de calor são extraídos a partir das imagens NOAA/AVHRR convertidas em parâmetros físicos de reflectância e temperatura de brilho (Deppe et al. 2003), a partir da utilização de métodos condicionantes pré-definidos e calibrados para o estado do Paraná (Kaufman et al. 1990, Arino et al. 1993, Kennedy et al. 1993). O estado da vegetação é caracterizado através de imagens de IVDN (Índice de Vegetação por Diferença Normalizada), extraídas a partir da utilização de imagens NOAA/AVHRR (Bandas 1 e 2). Os índices de vegetação caracterizam o vigor vegetativo e conseqüentemente a potencialidade de combustão. Ainda com relação a dados dinâmicos, os índices de Risco de Incêndio Florestal referem-se ao Índice Monte Alegre (Soares 1998, Pezzopane et al. 
2001, Batista et al. 2002), o qual é produzido a partir de parâmetros meteorológicos (umidade do ar, precipitação e número de dias sem precipitação).

O sistema combina a habilidade de cruzar e compor informações em diferentes layers com a facilidade de gerar informações estratégicas (figura 1). Sendo assim, aumenta a capacidade de identificar como falso alarme os focos de calor detectados pelas imagens NOAA/AVHRR. Por exemplo, comparando-se a informação da localização dos focos de calor com o estado de vegetação (IVDN), índice de Risco de Incêndio Florestal (RIF), rodovias e rede de drenagem, pode-se avaliar criteriosamente se um determinado foco de calor, representa ou não um caso de incêndio.

Vinculados a determinados layers ainda existem informações logísticas que são facilmente consultadas, tais como: (i) telefones, e-mails, corpo efetivo, número e caracterização de veículos dos Grupamentos do Corpo de Bombeiros, (ii), idem para os escritórios regionais do Instituto Ambiental do Paraná (IAP) e Postos da Polícia Florestal (PR), (iii) nome das rodovias, (iv) nome dos rios, (v) tipo de unidade de conservação, (vi) classe de uso e cobertura do solo, (vii) nome dos municípios e população, etc.

A infra-estrutura operacional utilizada inclui um sistema de recepção de imagens de satélites NOAA, Global Imaging (www.globalimaging.com), instalado no prédio do SIMEPAR, rede telemétrica de estações meteorológicas do SIMEPAR, estruturas computacionais de armazenamento de dados, e estações de trabalho (Unix e Windows). A plataforma SIG se refere ao software ArcView GIS 3.2 e suas extensões Spatial Analyst e Network Analyst.

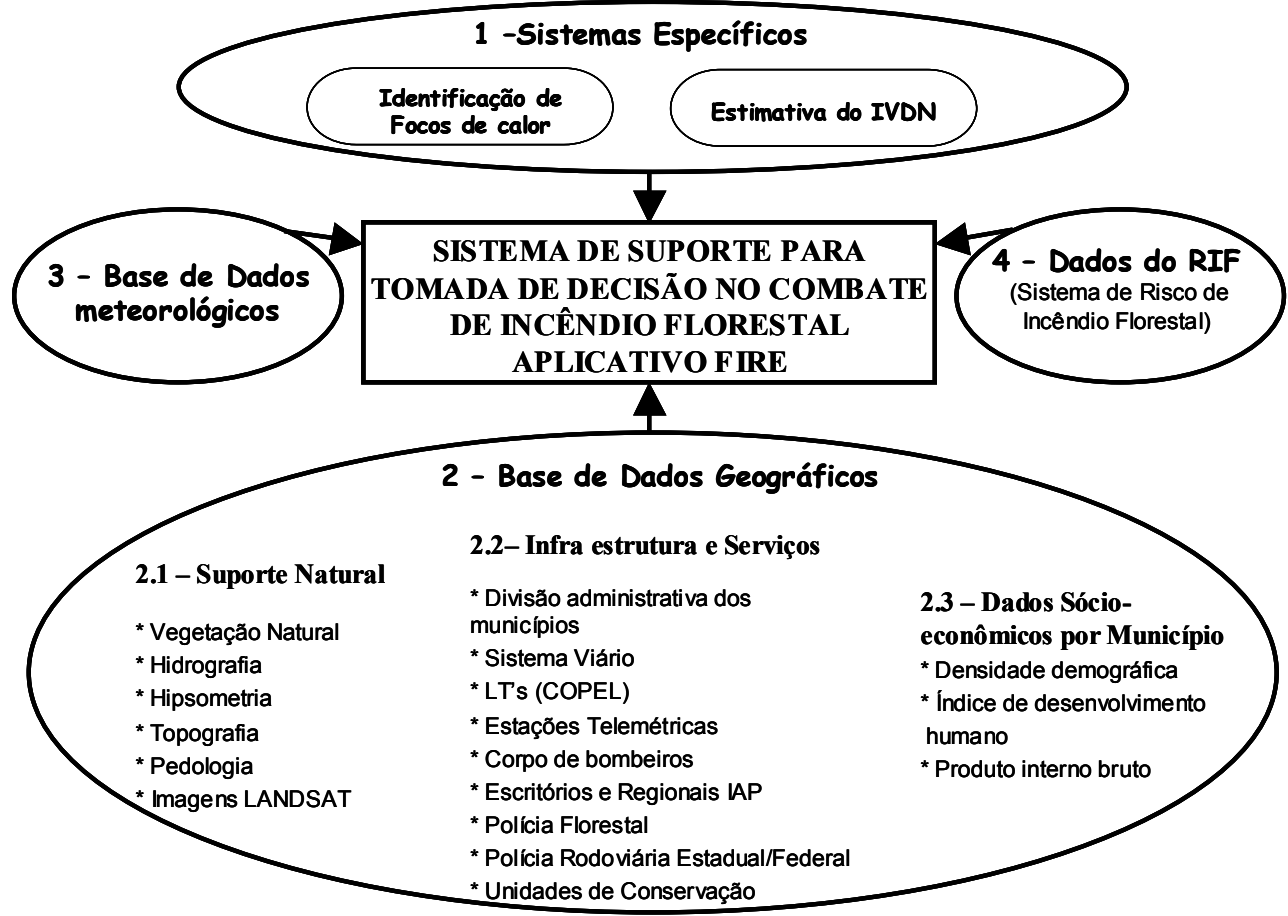

Figura 1: Organograma do sistema FIRESIG

Figure 1: FIRESIG flowchart

\section{RESULTADOS E CONCLUSÕES}

O FIRESIG foi desenvolvido para ser utilizado na avaliação de risco, detecção e combate de incêndios através da montagem de estratégias (figura 2). De acordo com as vantagens oferecidas, bem como qualidade e conteúdo dos dados e informações produzidos, o sistema pode ser considerado como possuir uma ótima relação custo/benefício.

As figuras 3 a 8 apresentam telas demonstrativas de operação do sistema, quando da ocorrência do incêndio do Parque Nacional de Ilha Grande, PR (2003). Na 
primeira tem-se a visualização dos focos de calor sobrepostos ao índice de Risco de Incêndio Florestal. $\mathrm{Na}$ tela seguinte aproximou-se a região do Parque Nacional de Ilha Grande, onde se percebe uma concentração de focos de calor, sob uma área com baixo IVDN e conseqüentemente alto potencial de combustibilidade. Na tela da figura 5 carregou-se uma imagem Landsat para verificação da cobertura do solo na região do possível incêndio. As três últimas telas demonstram a elaboração e posterior definição de uma estratégia de combate ao incêndio selecionado. Na figura 6 estão ilustrados os layers com as informações logísticas (rodovias, grupamentos do corpo de bombeiros, escritórios do IAP), através do uso do Menu Estático. A figura 7 ilustra a seleção de um dos focos de calor sobre a região de Ilha Grande e suas respectivas propriedades (coordenadas, altitude, tipo de vegetação e IVDN). Na última tela, através da ferramenta de identificação de rota, verifica-se a distância do menor caminho entre o foco selecionado e o grupamento do corpo de bombeiros mais próximo, bem como o nome da rodovia.

A utilização do sistema permite a produção de informações vitais para a tomada de decisão e planejamento de ações em relação ao combate de incêndios, em tempo quase real, com alta resolução temporal (dados diários), e em um contexto regional. Estas são características importantes do sistema, do qual podem ser extraídas informações para subsidiar o efetivo combate a incêndios, e não somente informações e espacialização de focos de calor. Em função da possibilidade de customização da interface, o sistema demonstra-se de fácil operação. Os dados e informações dinâmicas (focos de calor, risco de incêndio e índice de vegetação), os quais exigem atualização diária, podem ser carregados automaticamente pelos usuários. Em função da utilização de uma plataforma de SIG, destaca-se que o sistema pode ser ampliado para outras aplicações relacionadas ao monitoramento e planejamento de ações para o combate de acidentes e catástrofes naturais, tais como vazamento de produtos químicos e ocorrências de inundações.

Os usuários diretos se referem ao Instituto Ambiental do Paraná (IAP) e a Coordenadoria Estadual de Defesa Civil. Esta criou, em 1998 o Plano Estadual de Prevenção e Combate a Incêndios Florestais do Estado do Paraná (PREVIFLOR), o qual passará a adotar o presente sistema. Sendo assim, o Governo do Estado do Paraná passará a contar operacionalmente de um sistema de monitoramento e combate de incêndios, com conseqüências positivas, tais como, a preservação ambiental, redução de emissões, redução de perdas econômicas causadas por incêndios. O sistema possui caráter inovador devido ao fato de fornecer informações em tempo quase real, de alta resolução temporal, média resolução espacial, além do aspecto de abrangência regional.

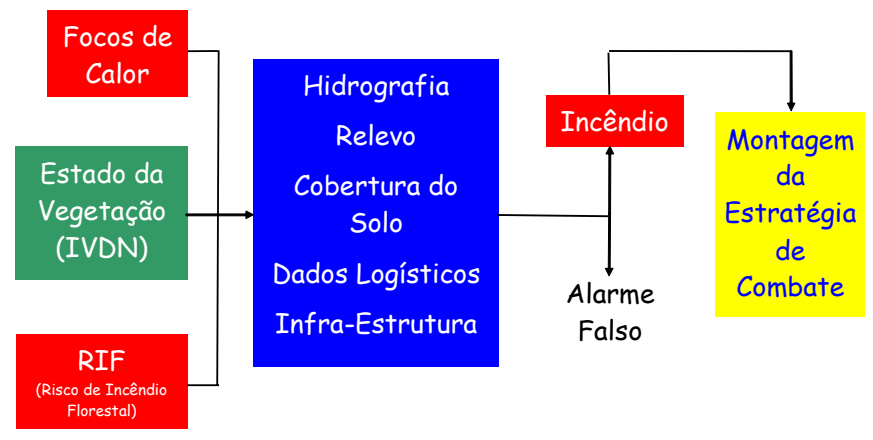

Figura 2: Fluxograma para montagem de estratégias de combate

Figure 2: Flowchart for fire fight strategy 


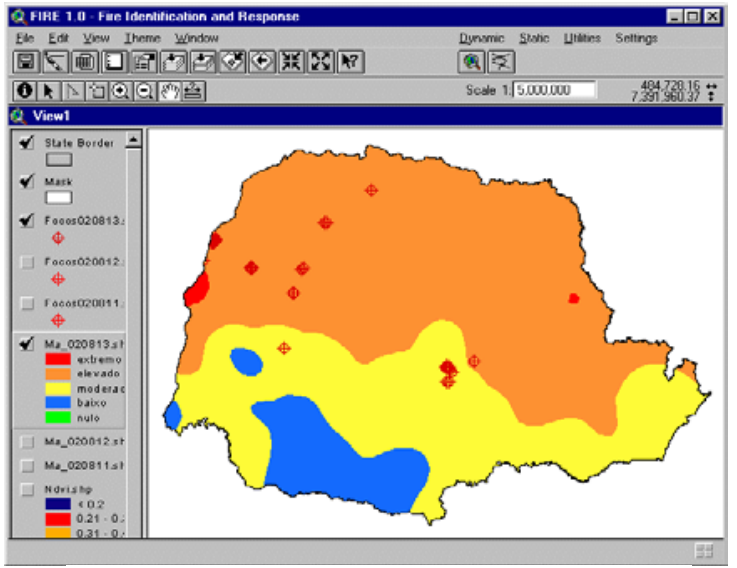

Figura 3 - Risco de incêndio Figure-Fire risk

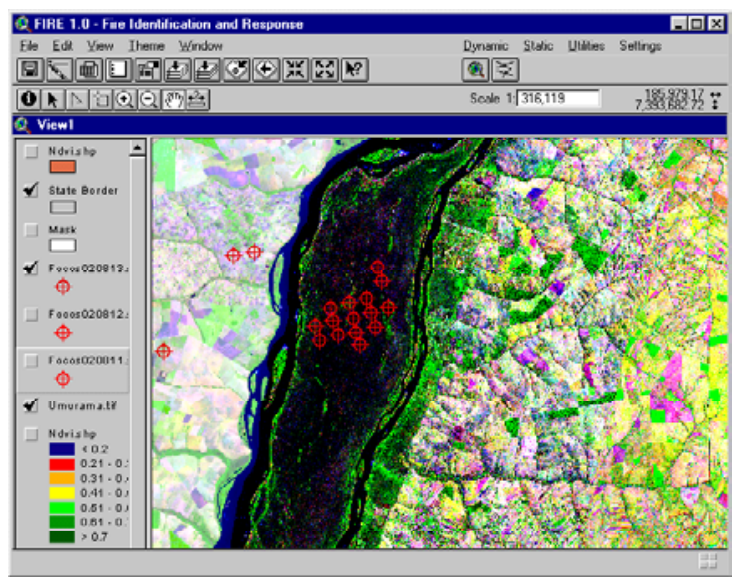

Figura 5 - Imagem LANDSAT (bandas 5,4,3) Figure 5 - Landsat image (bands 5,4,3)

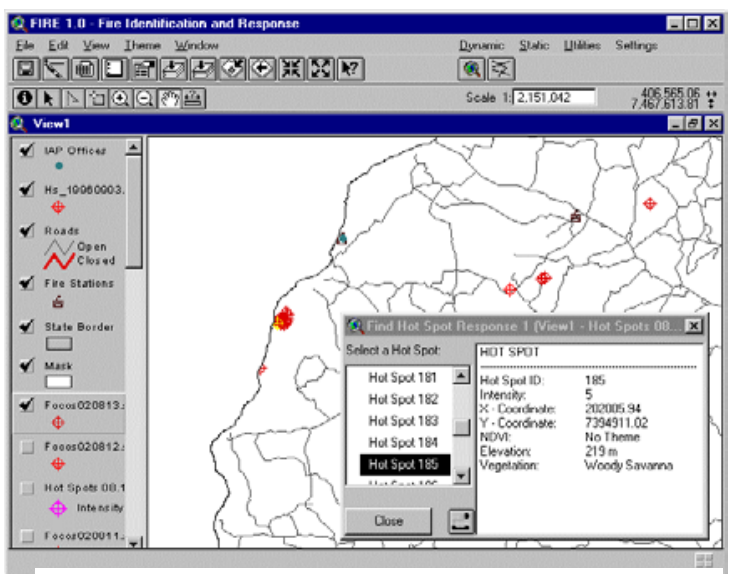

Figura 7 - Elaboração de estratégia de combate Figure 7 - Strategy build up

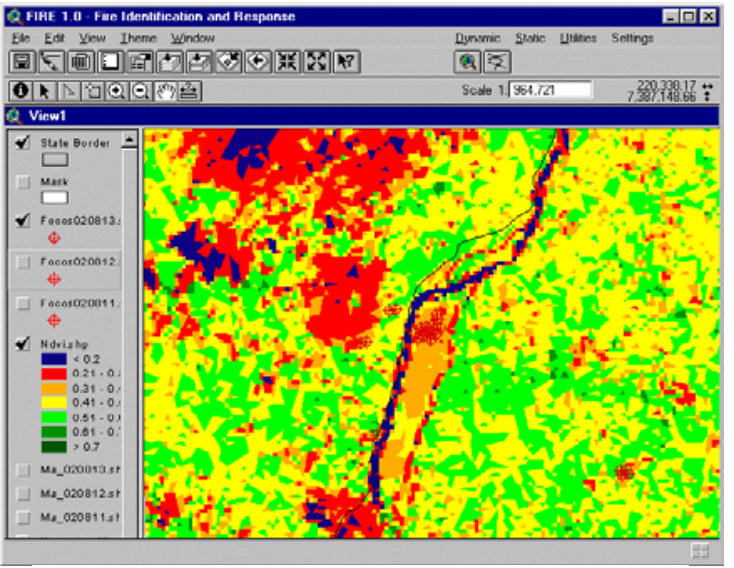

Figura 4 - Estado da Vegetação Figure 4 - Vegetation condition

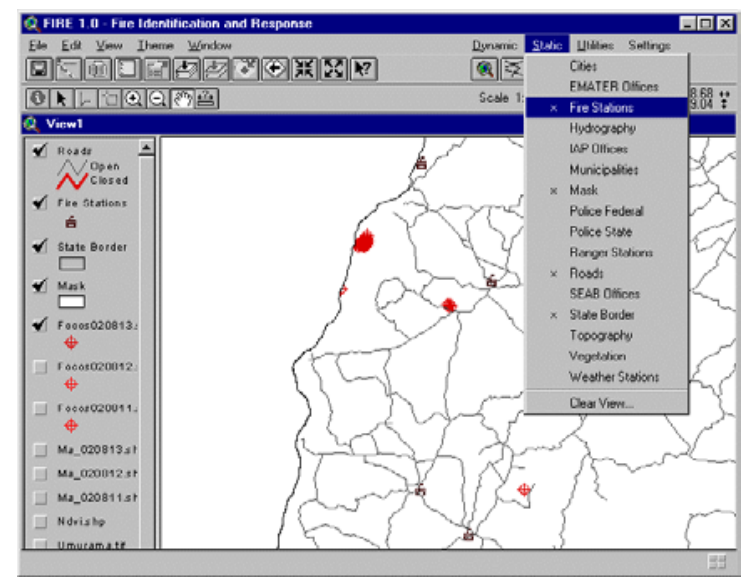

Figura 6 - Inserção de dados logísticos Figure 6-Logistic data imput

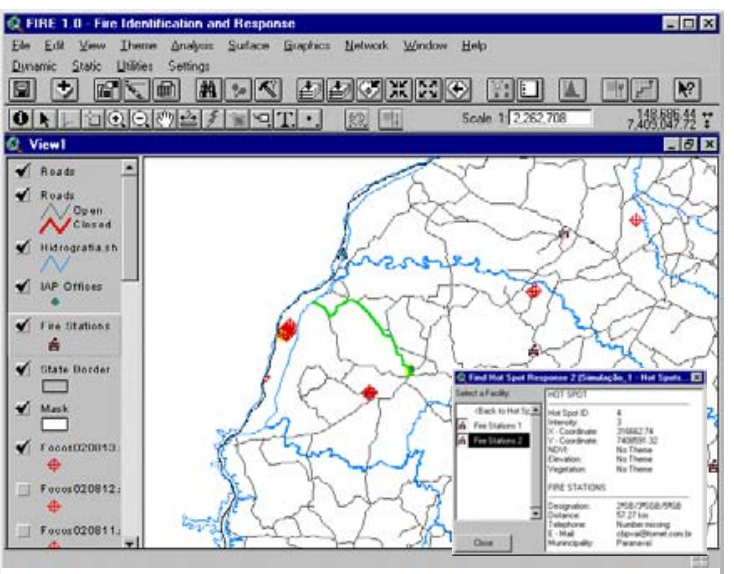

Figura 8 - Definição de estratégia de combate Figure 8 - Stratefy definition 


\section{REFERÊNCIAS}

ARINO, O.; MELINOLTE, L.; CALABRESI, G. Fires, Cloud, Land, Water: The Ionia AVHRR CD-Browser of ESRIN. EOQ 41, ESA, ESTEC, Noordwijk. 1993.

BATISTA, A. C.; OLIVEIRA, D. S.; SOARES, R. V. Zoneamento de risco de incêndios florestais para o estado do Paraná. FUPEF, Série Técnica N 02/02. 2002.

DEPPE, F.; PAULA, E. V.; PRATES, J. E. Monitoramento de incêndios e do estado da vegetação através da utilização de imagens NOAA/AVHRR. Anais XI SBSR, Belo Horizonte, Brasil, 05 - 10 abril 2003, INPE, P. 453-460. 2003.

KAUFMAN, Y. J.; TUCKER, C. J.; FUNG, I. Remote Sensing of Biomass Burning in the Tropics. Journal of Geophysical Research, V. 95, N. D7, P. 9927 - 9939. 1990.
KENNEDY, P. J.; BELWARD, A. S.; GREGOIRE, J. M. An Improved Approach to FIRES monitoring in West Africa using AVHRR data. International Journal of Remote Sensing, V. 15, P. 2235 - 2255. 1993.

PEZZOPANE, J. E. M.; NETO, S. N. O.; VILELA, M. F. Risco de incêndios em função da característica do clima, relevo e cobertura do solo. Revista Floresta e Ambiente, V. 8, N. 1, P. $161-166.2001$.

SCHOPPENHORST, J. A fire early warning and decision support system for the state of Paraná, Brazil. Christian Albrechts University, Alemanha. Dissertação de mestrado. 2002.

SOARES, R.V. Desempenho da "Fórmula de Monte Alegre" índice brasileiro de perigo de incêndios florestais. Revista Cerne, v. 4, n. 1, p. 087-099. 1988. 